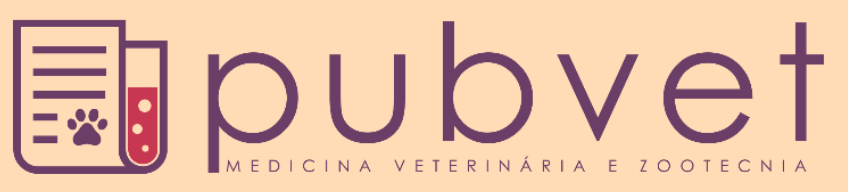

https://doi.org/10.31533/pubvet.v15n11a975.1-5

\title{
Tráfico de animais silvestres e seus impactos no meio
}

\author{
Daniela Ferreira Duarte ${ }^{1 *}$, Tamires Alves de Souza Fernandes ${ }^{1 \bullet}$, Adriane Araujo Waldige ${ }^{1 \bullet}$, \\ Thainá Souza Silva ${ }^{1}$, Bruna Rissas Generassa dos Santos ${ }^{1}$, Thamires Fernanda Ferreira ${ }^{1}{ }^{\circ}$, Julia \\ Navarro Alves ${ }^{10}$, Andresa Yamada Cruz da Silva ${ }^{1}$, Anderson Scherer ${ }^{2}$ \\ ${ }^{1}$ Estudante de Ciências Biológicas, Universidade Anhembi Morumbi, Escola de Ciências da Saúde. São Paulo-SP Brasil. \\ ${ }^{2}$ Professor da Universidade Anhembi Morumbi, Comunicação Clínica e Projeto de Integração Saúde e Comunidade, São Paulo - SP Brasil \\ *Autor para correspondencia, E-mail: danieladuarte.1995@outlook.com
}

Resumo. O contrabando de animais silvestres é a terceira prática ilícita mais lucrativa no mundo, ficando atrás apenas do tráfico de armas e o de drogas. Diversos fatores contribuem para que essa atividade tenha um desenvolvimento assaz como, por exemplo, as condições socioeconômicas de fornecedores e intermediários, carência em educação ambiental, deficiências nos métodos de controle e agentes dispostos para combate, grande número de receptores e alto lucro financeiro. $\mathrm{O}$ comercio ilegal de animais acarreta inúmeros danos a vários setores da sociedade, o que fomenta a perda de táxons ocasionando prejuízos à ciência, haja vista que servem para pesquisa e elaboração de diversas substâncias extremamente lucrativas das quais o Brasil não obtém ganho financeiro ou científico; além dos maus-tratos intensivos que sofrem os animais nesses processos, onde, apenas $10 \%$ chega com vida útil, sendo os outros $90 \%$ descartados sem adesão de protocolos de biossegurança. $\mathrm{O}$ tráfico de animais ocasiona desequilíbrio nos ecossistemas que sofrem danos diretos e indiretos devido as mudanças que impactam em cadeias alimentares, evolução e adaptação dessas espécies e em espécies que interagem com elas. Ainda contribui para instabilidade e danos à saúde pública, pois uma ampla série de zoonoses são disseminadas pelo contato humano-animal por patógenos que não temos imunidade e fármacos para combater.

Palavras-chave: Tráfico, lucro, zoonoses, danos

\section{Wild animals trafficking and its impacts on the environment}

Abstract. Wild animal smuggling is the third most lucrative illegal practice in the world, second only to weapons and drugs trafficking. Several factors contribute to the development of this activity, such as, the socioeconomic conditions of suppliers and intermediaries, lack of environmental education, deficiencies in control methods and agents willing to fight, large number of recipients and high financial profit. The illegal animal trade causes countless damages to various sectors of society, which fosters the loss of taxa causing damage to science, since they are used for research and development of several extremely lucrative substances from which Brazil gets no financial or scientific gain; in addition to the intensive mistreatment that animals suffer in these processes, where only $10 \%$ arrives with useful life, and the other $90 \%$ are discarded without adherence to biosecurity protocols. Animal trafficking causes unbalance in ecosystems that suffer direct and indirect damage due to changes that impact food chains, evolution and adaptation of these species and the species that interact with them. It also contributes to instability and damage to public health, as a wide range of zoonoses are spread through human-animal contact by pathogens that we have no immunity and no drugs to fight. processes, where only $10 \%$ arrives with useful life, and the other $90 \%$ are discarded without adherence to 
biosecurity protocols. Besides all the problems mentioned above, we have the damage to public health as aggravating factors of this illegal activity.

Keywords: Trafficking, profit, zoonoses, damage

\section{Introdução}

Animais silvestres são aqueles que vivem em um ambiente natural e que não têm contato (ou não deveriam ter) com os seres humanos (Deutsch \& Puglia, 1990; Pinheiro et al., 1989).

De acordo com o Tribunal de Justiça do Distrito Federal e dos Territórios, o crime de tráfico de animais silvestres está inserido no inciso III do artigo 29 da lei de 1998, que pró́be a venda, exportação, aquisição, guarda em cativeiro ou transporte de ovos ou larvas, sem devida autorização, sendo assim conseguimos entender que possuir animais silvestres como bichos de estimação é considerado ilegal se não devidamente autorizado ou com licença para tal.

O animal silvestre quando adquirido de forma ilegal como um animal de estimação, ou até mesmo nascido em um criadouro que seja legalizado, quando é impedido de viver em seu habitat natural sofre muito, devido a ruptura brusca entre um ecossistema onde ele pode se relacionar com outros animais, se reproduzir e se alimentar de forma apropriada, comparado a um local doméstico ou um cativeiro, pois, para terem o seu comportamento natural, esses animais possuem necessidades que são muito específicas que na maioria das vezes são desconhecidas pelas pessoas. Sabemos que espécies silvestres possuem funções ecológicas que espécies consideradas domésticas acabam por não possuir, por terem sido selecionadas pelos humanos e por se diferenciarem das espécies que lhe deram origem ao longo de muitas gerações, tanto fenotipicamente quanto geneticamente.

\section{Metodologoa}

Foram realizadas pesquisas sobre trabalhos de maior importância referentes ao assunto (meios de ação dos traficantes, impactos nos ecossistemas naturais e na Saúde Pública). Usou-se no desenvolvimento deste trabalho artigos científicos, livros acadêmicos, site de conteúdo educacional, sites de ONG'S; todos os itens foram previamente selecionados e analisados individualmente, onde, de cada conteúdo estudado, foram retiradas e reunidas informações sobre o tema do proposto, de modo a uni-las em apenas um artigo.

\section{Tráfico de animais silvestres e seus impactos ambientais e prejuízos aos ecossistemas}

Nos dias atuais, o tráfico de animais silvestres está como a terceira atividade, que é proibida por lei, mais lucrativa, perdendo apenas para o tráfico de armas e drogas (Nassaro, 2010). O Brasil é o principal fornecedor para o tráfico de animais e alguns conseguem estimar que aproximadamente quatro milhões de animais silvestres são comercializados ilegalmente por ano no Brasil (Alvarenga, 2016; Nassaro, 2010). De acordo com o RENCTAS, (2001) a cada 100 animais capturados ilegalmente no país, 70 são vendidos em território nacional e 30 são destinados ao exterior.

O principal alvo da biopirataria é a Floresta Amazônica, que concentra $70 \%$ da biodiversidade do planeta, de acordo com a ONG Pensamento Verde (2017). Todavia, outros biomas brasileiros não ficam fora do alvo dos traficantes, prova disso é atualmente só existir $10 \%$ da mata atlântica original, o que acaba concentrando centenas de espécies seriamente ameaçadas de extinção, que são obrigadas a lidar com o ritmo de destruição e o tráfico propriamente dito (Rodrigues et al., 2007). A ONG Pensamento Verde (2017) também menciona o cerrado, a caatinga, o pantanal e até os manguezais, remanescentes como ecossistemas, que também sofrem com esse "negócio".

De acordo com Belarmino (2008), as regiões Norte, Nordeste e Centro-Oeste são os principais alvos dos traficantes. A maioria dos recursos são levados para o Sul e Sudeste do País, além dos destinos internacionais, sendo os principais receptores os EUA e os países Europeus (Belarmino, 2008). Um exemplo do impacto dessas ações são as espécies exóticas invasoras, aquelas que quando estão em territórios novos, acabam se proliferando, dispersando e persistindo causando danos a espécies e ecossistemas nativos (Campos et al., 2006).

Em ressalva, apesar de muitos não saberem, os pesquisadores também são responsáveis pela prática 
de biopirataria (Belarmino, 2008). Estes, por muitas vezes estrangeiros, vêm ao Brasil e entramem contato com comunidades carentes, que possuem informações sobre determinados animais, no qual eles exportam e desenvolvem produtos farmacêuticos pelas informações genéticas (Belarmino, 2008); assim surrupiando o patrimônio natural, além da apropriação de conhecimento tradicional, segundo a ONG Pensamento Verde (2017).

Por conta disso, o Brasil perde anualmente em torno de US\$ 1,5 bilhão de bens naturais. Sendo, portanto, responsável por cerca de $15 \%$ do tráfico de animais silvestres e movimentando mundialmente entre US\$ 10 bilhões e US\$ 20 bilhões por ano (RENCTAS, 2001). O que fica nítido a partir desse ponto, é que a sociedade em si também é afetada, como pela não taxação de impostos em cima de produtos feitos a partir de elementos da nossa biota, o que implica em perdas econômicas e, principalmente, pelos efeitos sobre o ambiente que começam a entrar em desequilíbrio e que afetam tanto a população humana quanto a fauna (Ester \& Pitta, 2008).

Em acréscimo, a CPIBIO (2006) subdivide a biopirataria em lato sensu e em stricto sensu. A primeira incluía a exploração e o comércio ilegais de madeira, o tráfico de animais e plantas silvestres, já a última tange o acesso irregular ao patrimônio genético nacional e aos conhecimentos tradicionais associados (Belarmino, 2008). Segundo a ONG PROFAUNA, a retirada constante de indivíduos de uma mesma espécie pode levar a extinções locais ou totais, além de afetar outras espécies, inclusive a flora, com que se relacionam. Portanto, sendo um facilitador para o cruzamento entre parentes, o que empobrece a diversidade genética e dificulta a adaptação desses animais no processo evolutivo e diminuindo a possibilidade de deixar descendentes que melhor se adaptariam ao meio (RENCTAS, 2001).

Para serem transportados com maior facilidade, esses animais acabam passando por uma série de maus tratos. Muitas vezes são dopados, majoritariamente por álcool, machucados na coleta ou captura, sofrem lesões, como ossos quebrados de modo proposital para facilitar o transporte, pois assim ficam paralisados pela dor (Redford, 1992). Além disso, são transportados amontoados em pequenos espaços, sem ventilação, alimentação ou água, o que causa estresse e queda na imunidade e que pode acarretar morte, como é mencionado pelo site da PROFAUNA. Por fim, muitos são descartados por não estarem nos padrões que é exigido pelo destinatário (Belarmino, 2008), fora isso é frequente as fêmeas serem mortas durante a captura de filhotes, que muitas vezes também morrem (RENCTAS, 2001). Não só isso, mas ainda hoje muitos dos que morrem teriam suas penas arrancadas, os dentes ou qualquer outra parte de seus corpos destinados a artigos de luxo (CISS, 2019).

Em suma fica transparente que o tráfico de animais silvestres, ou a biopirataria, não é apenas desacato às leis, mas também de devastação e crueldade, uma vez que o comércio desses animais capturados na natureza sempre foi uma atividade deletéria para a fauna (Rodrigues et al., 2007), que extingue diversos animais e que muitas vezes perpetua o pensamento colonizador. Ainda hoje as populações detentoras de conhecimento tradicionais não recebem nada dos lucros de empresas de países desenvolvidos que patenteiam diversos fármacos e produtos de espécies endêmicas (Belarmino, 2008), além de que esses seres acabam sendo tratados nada menos do que peças que podem ser facilmente descartadas, não importando as consequências que sofrerem do começo ao fim e é claro do equilíbrio ecológico que acaba por prejudicado, como mencionado pelo ONG Pensamento Verde (2017).

Além dos problemas supracitados, a disseminação de zoonoses de amplo impacto na saúde pública pode ser mencionado como um agravante para essa prática. Segundo Fio Cruz, uma alta porcentagem, entre $70 \%$ e $80 \%$ das doenças infecciosas tem origem zoonótica. Isso porque animais silvestres podem ser portadores ou reservatório de doenças. E sua criação como animal de estimação pode aumentar bastante o risco de contágio humano, principalmente no Brasil onde a maioria desses animais são capturados ilegalmente na natureza.

A transmissão pode ocorrer de forma direta, principalmente pelo contato com secreções (saliva, sangue, urina, fezes) ou contato físico como arranhaduras ou mordeduras. De forma indireta (Quadro 1), pode acontecer por meio de vetores como mosquitos e pulgas, por contato indireto com secreções, pelo consumo de alimento contaminado com o agente (viral, bacteriano, fúngico ou parasitário), entre outras (Acha \& Szyfres, 2003). A capacidade de transmissão é influenciada pelo período de incubação, densidade populacional, práticas agropecuárias, estabilidade do agente, virulência do agente (AgudeloSuárez, 2012). Os agentes responsáveis por desencadear essas alterações podem ser microrganismos 
diversos, tais como, vírus, bactérias, fungos, protozoários entre outros (Acha \& Szyfres, 2003). De acordo com a definição de zoonoses proposta pela OMS existem mais de 200 doenças transmissíveis que podem ser caracterizadas como zoonoses (Avelar et al., 2019).

Quadro 1. Classificação das zoonoses segundo os ciclos de manutenção do agente etiológico

\begin{tabular}{|c|c|c|c|}
\hline Classificação & Definição & \multicolumn{2}{|c|}{ Exemplo } \\
\hline $\begin{array}{c}\text { Zoonoses } \\
\text { diretas: }\end{array}$ & $\begin{array}{c}\text { O agente pode persistir com passagens } \\
\text { sucessivas por uma única espécie de } \\
\text { animal vertebrado. }\end{array}$ & \multicolumn{2}{|c|}{ Raiva canina. } \\
\hline Ciclozoonoses: & $\begin{array}{c}\text { O agente necessita obrigatoriamente } \\
\text { passas por duas espécies distintas de } \\
\text { animais vertebrados para que o seu ciclo } \\
\text { completo. }\end{array}$ & $\begin{array}{c}\text { As doenças em que o ciclo } \\
\text { biológico completo do } \\
\text { agente etiológico necessita } \\
\text { obrigatoriamente da } \\
\text { passagem por seres } \\
\text { humanos e animais. }\end{array}$ & $\begin{array}{c}\text { Doenças em que o ciclo } \\
\text { biológico pode se } \\
\text { completar com dois } \\
\text { animais vertebrados, } \\
\text { porém, que }\end{array}$ \\
Metazoonosentualmente podem \\
atingir seres humanos.
\end{tabular}

Fonte: adaptado de Zoonoses Conceito (2021).

\section{Considerações finais}

Embora o tráfico de animais silvestres seja um crime previsto em lei, ainda ocorre de forma exponencial, afetando a biodiversidade, a sociedade, a econômia, a ciência, a Saúde Pública, entre diversos outros setores. A falta de fiscalização, de investimento em gestão ambiental e campanhas de concientização, além da impunidade fomentam o biotráfico, que é mantido pelo ciclo de retirada, compra e venda desses animais do ecossistema nativo e incentivado pelo lucro financeiro que a rede de tráfico obtém a partir disso.

Os danos e prejuízos ocasionados pelo comércio ilegal de animais silvestres impactam diferentes esferas da sociedade, ocasionando mudanças, muitas vezes, irreversíveis nos ecossistemas, como perdas genéticas, e potenciais campos de pesquisa. Em consequência há extinção de espécies, além do surgimento de zoonoses ocasionadas pelo contato com seres silvestres sem os protocolos de biossegurança necessários, entre outros.

Evidencia-se a necessidade do reforço aos órgãos de fiscalização e punição para que os responsáveis não encontrem facilidade no desenvolvimento e execução desse crime, bem como a importância na implementação e investimento em programas de educação ambiental.

\section{Referências bibliográficas}

Acha, P. N., \& Szyfres, B. (2003). Zoonosis y enfermedades transmisibles comunes al hombre ya los animales: clamidiosis, rickettsiosis y virosis. 3. Pan American Health Organization.

Agudelo-Suárez, A. N. (2012). Aproximación a la complejidad de las zoonosis en Colombia. Revista de Salud Pública, 14, 325-339.

Alvarenga, L. J. (2016). Tráfico de animais silvestres: historiografia e lógicas de continuidade. $M P G$ Jurídico: Revista Do Ministério Público de Minas Gerais, 1, 33-39.

Avelar, A. C. S., Donida, C. C., \& Pavanelli, G. C. (2019). Revisão integrativa das principais zoonoses de ocorrência brasileira. Anais Eletrônicos Do XI EPCC - Encontro Internacional.

Belarmino, A. I. N. (2008). A biodiversidade brasileira e os prejuízos da biopirataria. Florianópolis.

Campos, J. B., Tossulino, M. de G. P., \& Müller, C. R. C. (2006). Unidades de conservação: ações para valorização da biodiversidade. Instituto ambiental do Paraná.

CISS - Centro de Informação de Saúde Silvestre. (2019). Tráfico de animais silvestres traz riscos à 
biodiversidade e ameaças à saúde silvestre e humana. Fiocruz, 12(3) https://www.biodiversidade.ciss.fiocruz.br/sites/www.biodiversidade.ciss.fiocruz.br/files/bole tim\%20informativo_edicaofinal.pdf. Acesso dia 27 mar. 2021.

CPIBIO (org.). (2006) Comissão Parlamentar de Inquérito Destinada a Investigar o Tráfico de Animais e Plantas Silvestres Brasileiros, a Exploração e Comércio Ilegal de Madeira e a Biopirataria no País: Departamento de polícia Federal. Relatório final. Disponível em: http://camara.gov.br. Acesso dia 27 mar. 2021.

Deutsch, L. A., \& Puglia, L. R. R. (1990). Os animais silvestres: proteção, doenças e manejo. Globo.

Ester, A., \& Pitta, T. (2008). O conceito do desenvolvimento sustentável. Revista Terceiro Setor \& Gestão, 2(1), 22-28.

Nassaro, A. L. F. (2010). O tráfico de animais silvestres no brasil. Periódico Eletrônico Fórum Ambiental Da Alta Paulista, 6(5), 1-10.

OMS. Organização Mundial da Saúde. Zoonoses. Disponível em: http://www.who.int/topics/zoonoses/en/. Acesso dia 04 de abr. 2021.

PROFAUNA (org.) [s.d]. Consequências do Tráfico de Animais. Disponível em: http://www.profauna.com.br/trafico/consequencias\#: :text=Crueldade\%3A,intenso\%2C\%20c ausando\%20queda\%20de\%20imunidade. Acesso dia 27 mar. 2021.

Pinheiro, M. J. P., Andrade, S. A., \& Cunha, J. N. (1989). Preservação e exploração de animais silvestres nativos: preá, cutia e mocó. Revista Caatinga, 6(1), 28-49.

Renctas (org.). (2001). $1^{\circ}$ Relatório Nacional sobre o Tráfico de Fauna Silvestre. Renctas. Disponível em: https://www.renctas.org.br/wp- content/uploads/2014/02/REL_RENCTAS_pt_final.pdf Acesso dia 27 mar. 2021.

Redação Pensamento Verde (org.). (2017). Conheça as consequências da biopirataria no Brasil, sua soluções ecomo evitar. Disponível em: https://www.pensamentoverde.com.br/meioambiente/conheca-consequencias-da-biopirataria- no-brasil-suas-solucoes-e-como-evitar/. Acesso dia 27 mar. 2021

Redford, K. H. (1992). The empty forest. Bioscience, 42(6), 412-422.

Rodrigues, R. E., Sibinelli, T. C., \& Leme, S. M. (2007). Tráfico de animais silvestres: aspectos jurídicos, influência no processo de extinção das espécies e suas consequiências ecológicas. Âmbito Jurídico, 1, 1-6.

Histórico do artigo:

Recebido: 8 de julho de 2021

Aprovado: 19 de agosto de 2021
Licenciamento: Este artigo é publicado na modalidade Acesso Aberto sob a licença Creative Commons Atribuição 4.0 (CC-BY 4.0), a qual permite uso irrestrito, distribuição, reprodução em qualquer meio, desde que o autor e a fonte sejam devidamente creditados. 